\title{
Sıçrama Sonrası Yere Iniş Hatası Puanlama Sistemi-Gerçek Zamanlı’nın Türkçe geçerlik ve güvenirlik çalışması
}

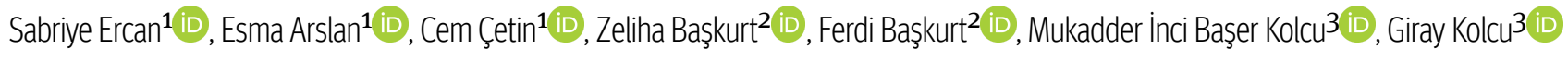 \\ ${ }^{1}$ Sports Medicine Department, Faculty of Medicine, Suleyman Demirel University, Isparta, Turkey \\ ${ }^{2}$ Physiotherapy and Rehabilitation, Faculty of Health Sciences, Suleyman Demirel University, Isparta, Turkey \\ 3Department of Medical Education and Informatics, Faculty of Medicine, Suleyman Demirel University, Isparta, Turkey
}

\section{ABSTRACT}

Objective: The purpose of this study is to conduct the validity and reliability study of Turkish version of the Landing Error Scoring System-Real Time (LESS-RT) and submit it for the use of relevant researchers.

Material and Methods: The study was designed as a validity study in the quantitative research design. The ten-item directive had been translated into Turkish. After the translation, an evaluation was performed in a group of 13 participants to determine comprehensibility, language and cultural conformity assessment and to receive expert opinion. Receiving the feedback with the completion of the evaluation, the Turkish version was finalized and submitted for implementation. Sixty-two participants (\%40.3 male, \%59.7 female) were subjected to the jump test in order to evaluate the Turkish version by two raters. The video recordings were obtained from the front and side during the jumps.

Results: The mean Item-Content Validity Index (I-CVI) was 0.91 (lowest 0.84; highest 1.00). The lowest expert proportion relevant for the scale item (S-CVI) was 0.80 and the highest was 1.00 and the Scale-Level Index/Average (S-CVI / Ave) value was 0.91. There are no differences between the first rater's (test: $6.84 \pm 1.85$; retest: $6.94 \pm 1.93 ; p>0.05$ ) and the second rater's (test: $6.37 \pm 1.46$; retest: $6.37 \pm 1.72 ; p>0.05)$ error scores ( $p>$

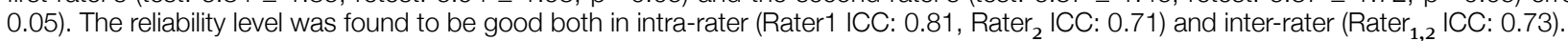

Conclusion: The validity and reliability of the LESS-RT in Turkish were accomplished. Thus, a practical system that facilitates the detection of landing errors is presented for the use of Turkish researchers and health professionals.

Keywords: Movement assessment, jump, landing

öz

Amaç: Bu çalışmanın amacı 'Sıçramadan Sonra Yere İniş Hatası Puanlama Sistemi-Gerçek Zamanlı'nın Türkçe geçerliğini ve güvenirliğini sağlamak ve bu sistemi sporcu sağlığı ile ilgilenen araştırmacıların kullanımına sunmaktır.

Gereç ve Yöntem: Çalıșma nicel araștırma deseninde geçerlik çalıșması olarak tasarlanmıștır. On maddelik yönerge Türkçeye çevrilmiștir. Çeviri çalıșması sonrasında, Türkçe yönergenin; dilini ve anlaşılırlığını incelemek, maddelerin kullanımında Türkiye'deki alan uzmanlarının dil ve kültürel uygunluğunu belirlemek amacı ile 13 kișilik bir grupta değerlendirme yapılmış ve uzman görüşü alınmıştır. Değerlendirme sonunda alınan geri bildirimler doğrultusunda Türkçe yönergeye son șekli verilerek uygulamaya hazır hale getirilmiștir. Alan uzmanı iki araștırmacı Türkçe yönergenin değerlendirici içi ve değerlendiriciler arası güvenirliğini saptamak için yaşı 18-25 yıl arasında olan, sıçrama testi yapmasına engel kas-iskelet sistemi yaralanması bulunmayan 62 (\%40.3 erkek, \%59.7 kadın) katııımcıyı orijinal araştırmada tarif edilen sıçrama testine tabi tutmuşlardır. Test-retest puanlama sonuçlarının, değerlendiriciler içi ve arası güvenirlik analizlerinin yapılabilmesi için sıçrama sırasında önden ve yandan video kamera ile kayıt alınmıştır.

Bulgular: Ölçeğin ortalama madde kapsam geçerlik indeksi değeri (I-CVI) 0.91 (en düşük 0.84; en yüksek 1.00) olarak belirlenmiştir. Ölçek maddeleri için en düşük ölçek kapsam geçerlik indeksi (S-CVI) 0.80, en yüksek ise 1.00 olarak belirlenmiştir. Ölçek-Kapsam Geçerlik Indeksi Ortalama (SCI/Ave)

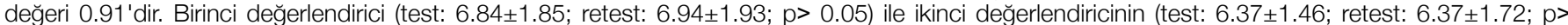
0.05 ) hata puanlamaları arasında fark yoktur ( $p>0.05$ ). Değerlendirici içi (Değerlendirici ${ }_{1}$ Sınıf İçi Korelasyon Katsayısı: 0.81, Değerlendirici ${ }_{2}$ Sınıf Içi Ko-

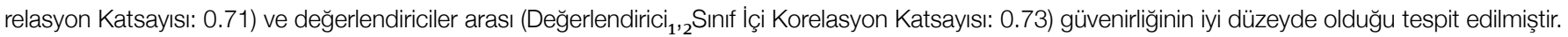

Sonuç: Sıçramadan sonra yere iniş hatası puanlama sistemi-Gerçek Zamanlı'nın Türkçe geçerliği ve güvenilliği sağlanmıştır. Böylece, sıçramadan sonra yere inișteki hataların tespit edilmesini kolaylaştıran pratik bir sistem Türk araştırmacıların ve sporcu sağlığı ile ilgilenen sağlık profesyonellerinin kullanımına sunulmuștur.

Anahtar Sözcükler: Hareket analizi, sıçrama, yere iniş 


\section{Giriș}

Tüm hastalıklarda olduğu gibi spor yaralanmalarında da riski öngörebilmek ve sporcuyu olası yaralanmalardan korumak önemlidir (1). Riski öngörebilmek için çeşitli klinik testlerin yanında hareket analizlerinin yapılmasına da ihtiyaç duyulmaktadır. İnsan hareketlerinin analiz edilmesinde altın standart olarak kabul gören yöntemler üç boyutlu hareket analizi sistemleridir (2). Uluslararası Olimpiyat Komitesi, alt ekstremite yaralanmalarında ve özellikle akut diz yaralanmalarında üç boyutlu kinematik sistemleri altın standart olarak belirlemiştir (3). Ancak altın standart olan bu yöntemlerin kullanılabilmesi uygun finansal durum, kullanıcı uzmanlığı, zaman ve analizlerin gerçekleştirilebileceği özel bir alan gerektirmektedir (2). Öte yandan sporcu sağlığı ile yakından ilgilenen spor hekimleri, spor fizyoterapistleri, antrenörler vb. gibi geniş bir grup, laboratuvar koşullarında gerçekleştirilebilen hareket analizlerinden çok ekonomik ve sahada uygulamaya olanak tanıyan hareket analizi yöntemlerini yeğlemektedirler (4).

Özellikle alt ekstremite yaralanma riskini öngörebilmek için klinik değerlendirmede kullanılabilen, üç boyutlu hareket analizi sistemleri ile iyi düzeyde uyum gösterdiği kanıtlanan analizlerden biri "Sıçramadan Sonra Yere İnişte Hata Puanlama Sistemi"dir (2). "Sıçramadan Sonra Yere İnişte Hata Puanlama Sistemi", sıçramadan sonra inişi başarı ile değerlendirip sporcuların alt ekstremite ve özellikle ön çapraz bağ yaralanma riskini öngörebilmektedir. Riski yüksek çıkan sporculara bireysel eğitim verilip sıçrama biyomekaniği düzeltildiğinde ise riskin azaldığı yine bu sistem ile belirlenebilmektedir. Klinik pratikte oldukça yararlı olan bu sistemin; iki video kameraya, sıçramaların kaydını alacak personele, video analizleri için uzmana ve zamana ihtiyaç duyması dezavantaj da oluşturabilmektedir (5). Tüm bu nedenleri göz önüne alan Padua ve arkadaşları, orijinal "Sıçramadan Sonra Yere İnişte Hata Puanlama Sistemi"ni modifiye ederek kamera kullanımından bağımsız olan gerçek zamanlı analiz sistemini geliştirmiştir (5).

Türkçe dil uyarlaması yapılmış hareket analizi sistemlerinin yeterli sayıda olmaması, klinik uygulamalarımızda zorluk oluşturmaktadır. Bu çalışmanın amacı "Sıçramadan Sonra Yere İnişte Hata Puanlama Sistemi-Gerçek Zamanlı"nın Türkçe geçerliğinin ve güvenirliğinin sağlanması, dil uyarlaması sonrasında sporcuların sıçramadan sonra yere iniş hatalarının değerlendirilmesi için sporcu sağlığı ile ilgilenen araştırmacıların kullanımına sunulmasıdır.

\section{GEREÇ ve YÖNTEMLER}

Çalışma, nicel araştırma deseninde geçerlik çalışması olarak tasarlanmıştır. Çalışma için e-posta yolu ile puanlama sisteminin geliştiricisi olan Darin Padua ile 7 Nisan 2019 ta- rihinde görüşülmüş ve izin alınmıştır. Araştırma, yerel etik kurul tarafından 7 Mayıs 2019 tarihli ve 158 sayılı karar ile onaylanmıştır.

\section{Türkçeye Uyarlama Çalışmaları}

Çalışmada ölçüm aracı olarak kullanılan "Sıçramadan Sonra Yere İnişte Hata Puanlama Sistemi-Gerçek Zamanlı"nın Türkçe olarak kullanılabilmesi için Souza ve Rjiianastrirat (2011) tarafından farklı dillerde oluşturulan ölçek ve ölçüm araçlarının ihtiyaç duyulan dillerde kullanılabilmesine olanak sağlayan kılavuzdan esinlenerek çeviri çalışması yürütülmüştür (6).

Birinci aşama olarak, on maddelik yönerge, etik kurul onayının alınmasından sonra, iyi seviyede İngilizce bilen ve birbirlerinden bağımsız, farklı alanlarda uzmanlığı olan ve daha önce ölçek uyarlama çalışması yürütmüş olan 6 kişilik (2 spor hekimi, 2 fizyoterapist ve 2 tıp eğitimcisi) bir ekip tarafından Türkçeye çevrilmiştir. Türkçeye çeviri aşamasında maddelerin orijinaline uygun ve ayn zamanda toplumumuzca anlaşılır olmasına özen gösterilmiştir.

Tüm çeviriler tamamlandığında, ikinci aşama olarak çeviri ekibi bir araya gelerek ölçüm aracındaki maddelerin kavramsal hataları ve tutarsızlıkları düzeltilmiş, dil ve kültür uyumu konusunda uzlaşma sağlanarak Türkçe yönergenin ilk şekli oluşturulmuştur.

Türkçeye çevirisi yapılan metin, uzman görüşü alınması ve pilot uygulama yapılması öncesinde farklı iki tercümanlık ofisi tarafından ana dil olan İngilizceye çevrilmiş ve araştırmacılar tarafından orijinal hali ile karşılaştırılmıştır. Orijinal dildeki metin ile sadece bağlaç vb. dile özgü teknik noktalarda farklılıklar bulunması nedeniyle Türkçe çevirisinin uygun olduğu kanaatine varılmıştır.

Türkçe yönergenin; dilini ve anlaşılırlığını incelemek, maddelerin kullanımında Türkiye"deki alan uzmanlarının dil ve kültürel uygunluğunu belirlemek amacı ile uzman görüşü alınmış ve bu kişilerce ön uygulama niteliğinde değerlendirme yapılmıştır. Değerlendirme işlemi, en az 2 yıllık mesleki tecrübesi olan fizyoterapist ve alan uzmanı hekimlerden oluşan 13 kişilik bir grupta gerçekleştirilmiştir. Değerlendirme sonunda yapılan kapsam geçerlik analizleri ve alınan geri bildirimler doğrultusunda çeviri ekibinde yer alan kişilerce ikinci bir tartışma oturumu gerçekleştirilmiş ve Türkçe test yönergesine son şekli verilerek uygulamaya hazır hale getirilmiştir (Ek 1). Görüşüne başvurulan uzman sayısı 13 olduğu için madde kapsam geçerlik indeksi (I-CVI) referans değer 0.78 ve üzeri (7), ölçek kapsam geçerlik indeksi (S-CVI) referans değeri de 0.80 ve üzeri olarak dikkate alınmıştır (8). 


\section{Çalışma grubu}

Çalışmanın örneklemini 62 birey oluşturmuştur. Çalışmaya; yaşı 18-25 yıl arasında olan, sıçrama testi yapmasına engel kas-iskelet sistemi yaralanması bulunmayan bireyler dahil edilmiştir. Yaşı 18 yıldan küçük, 25 yıldan büyük olanlar,kas-iskelet sistemi yaralanması bulunanlar (son 6 ayda alt ekstremite yaralanması geçiren, son 2 yılda alt ekstremitede fraktür ya da cerrahi öyküsü olan) çalışmaya alınmamıştır.

\section{Sıçrama testleri}

Türkçe yönergenin, değerlendirici içi ve değerlendiriciler arası güvenirliğinin değerlendirilebilmesi için katılımcılar orijinal araştırmada tarif edilen sıçrama testine tabi tutulmuştur (5).
Sıçrama için $30 \mathrm{~cm}$ yüksekliğinde, zemini kaygan olmayan ahşap bir kutu hazırlanmıştır. Sıçrama protokolü, araştırmacılar tarafından katılımcılara tek tek gösterilmiştir. Katılımcıların, en az bir kez deneme yapmasına izin verilmiştir. Uygulama sirasında herhangi bir sözel motivasyon ya da komut verilmemiştir.

Her bir katılımcı kutudan, kendi boy uzunluğunun yarısı uzaklıktaki mesafeye sıçramış, yere iniş ardından herhangi bir bekleme olmadan sıçrayabileceği en yüksek vertikal yüksekliğe sıçramıştır (Resim 1a, 1b, 2a, 2b). Tarif edilen bu sıçrama işlemi art arda 4 kez tekrar edilmiştir.

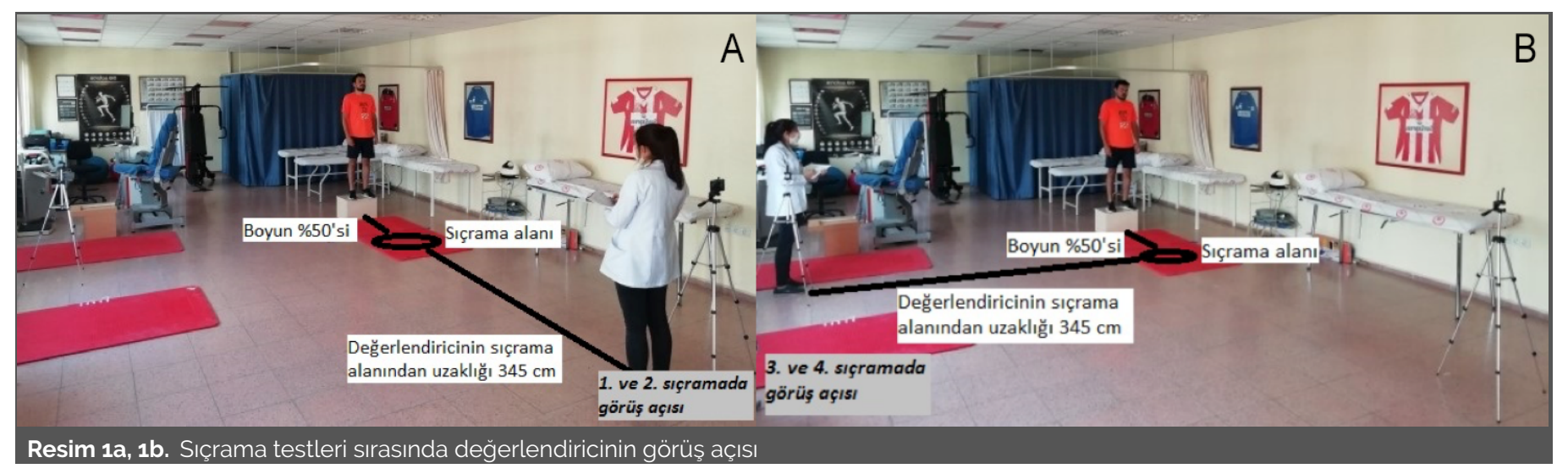

"Sıçramadan Sonra Yere İnişte Hata Puanlama Sistemi-Gerçek Zamanlı"nın kullanımında video kamera kaydı alınmas1 gerekmemektedir. Öte yandan araştırmamızın yöntemi gereği, değerlendiricilerin zamansal (o. gün belirlenen hata puanı ile 15. gün belirlenen hata puanı) tutarlılıklarını belirlemek için sıçramalar kamera kaydına alınmıştır. Sıçrama minderinin sağ yanına ve ön kısmına kamera özelliği olan akıllı telefonlar (Huawei FIG-LX1 model) sabitlenmiştir. Değerlendiricinin bulunduğu noktada, değerlendiricinin yanına yerleştirilen kameraların sıçrama minderinden uzaklığ $345 \mathrm{~cm}$, kamera lensinin yerden uzaklığ $122 \mathrm{~cm}$ olarak ayarlanmıştır. Değerlendiriciler içi ve arası güvenirlik analizlerinin yapılabilmesi için sıçrama sırasında önden ve yandan video kamera ile kayıt alınmıştır.

Siçrama testlerinin analizleri yapılmadan önce, birbirinden bağımsız olarak "Sıçramadan Sonra Yere İnişte Hata Puan- lama Sistemi" konusunda gerekli eğitim sürecini (4) tamamlamış olan değerlendiriciler (Değerlendirici ${ }_{1}$ : spor hekimliği uzmanı, Değerlendirici ${ }_{2}$ : spor hekimliği tıpta uzmanlık öğrencisi), Türkçe test yönergesini 1 saatlik bir oturum ile tartışıp uzlaşıya varmışlardır. Uzlaşı sonrasında kaydedilen görüntüler, video tabanlı ücretsiz hareket analizi programı (Kinovea versiyon 0.8.15, https://www.kinovea.org/) yardımıla o. günde (test) ve 15. günde (re-test) izlenmiştir. Kamera kayıtlarının amacı, değerlendiricilerin zamansal tutarlılıklarını incelemek olduğu için değerlendiriciler, hareket analizi programının açı ölçme, görüntü hızı ayarlama, görüntüyü geri sarma vb. gibi özelliklerini kullanmamış, görüntüleri tek seferde izleyip birbirlerinden bağımsız olarak o. günde (test) ve 15. günde (re-test) orijinal araştırmada tarif edilen şekilde puanlama yapmıştır. 


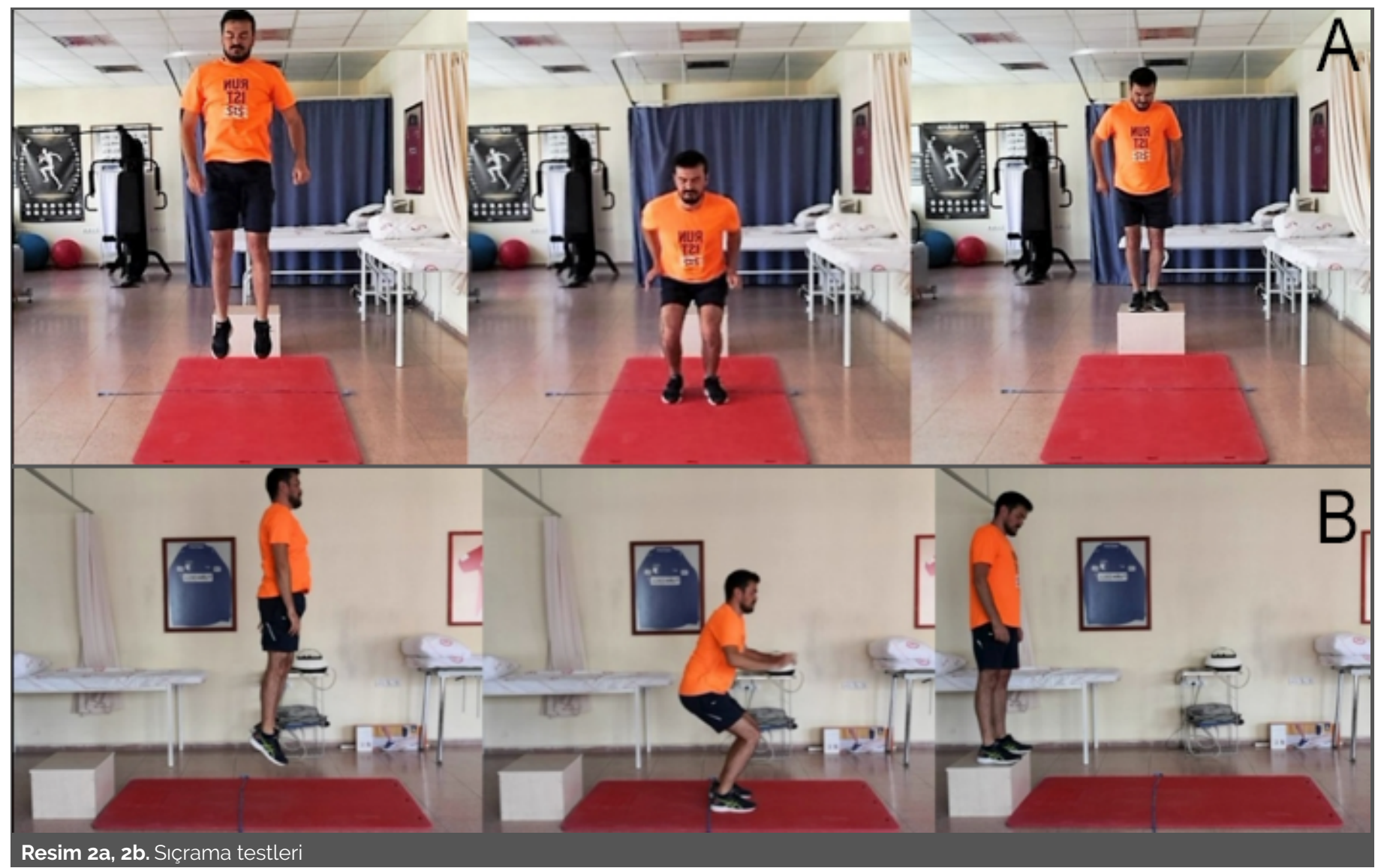

\section{İstatistiksel analiz}

Veriler SPSS v.23 paket programı ile analiz edilmiștir. Değerlendiricilerin verdiği "Sıçramadan Sonra Yere İnişte Hata Puanlama Sistemi-Gerçek Zamanlı" hata puanları, ortalama \pm standart sapma olarak sunulmuştur. Hesaplanan toplam puanlarda fark olup olmadığı bağımlı ve bağımsız gruplarda $t$ testi ile incelenmiştir. $\mathrm{P}$ değerinin 0.05 'in altında olması istatistiksel olarak anlamlı kabul edilmiştir.

Maddelerin ve ölçeğin kapsam geçerliliğini değerlendirmek için kapsam geçerlik indeks değeri incelenmiştir. Değerlendiriciler içi ve arası güvenirlik analizleri, sınıf içi korelasyon katsayısı (\%95 güven aralığı) ile yapılmıştır. Sınıf içi korelasyon katsayısı (4); 0.81-1.00 arasında mükemmel, o.610.80 arasında iyi, 0.41-0.60 arasında ise orta düzeyde kabul edilmiştir.

\section{BULGULAR}

"Sıçramadan Sonra Yere İnişte Hata Puanlama Sistemi-Gerçek Zamanlı"nın Türkçeye uyarlama çalışmaları sırasında öncelikle ölçüm aracının geçerliği, sonrasında ise yapılan analizlerin geçerliği değerlendirilmiştir.

"Sıçramadan Sonra Yere İnişte Hata Puanlama Sistemi-Gerçek Zamanlı" ölçüm aracının dil uygunluğunun değerlendirilmesi amacıyla alan uzmanlarından oluşan 13 kişilik bir ekip tarafından ölçüm aracının maddeleri incelenmiş, ön uygulama niteliğinde değerlendirmeler yapılmış ve araştırmacı ekibe geri bildirim verilmiştir. Bu aşama sonrasında tekrar bir araya gelen çeviri ekibi ve alan uzmanları tarafından gerekli düzenlemeler yapılmıştır.

Ölçeğe ilişkin hesaplanan madde kapsam geçerlik indeksi değeri (I-CVI) en düşük 0.84 , en yüksek 1.00 ve ortalama madde kapsam geçerlik indeksi değeri ise 0.91 olarak belirlenmiştir. Ölçek maddeleri için en düşük ölçek kapsam geçerlik indeksi (S-CVI) 0.80, en yüksek 1.00 ve Ölçek-Kapsam Geçerlik İndeksi Ortalama (SCI/Ave) değeri 0.91'dir.

\section{Ölçüm Aracı ile Yapılan Sıçrama Testi Sonuçları}

Çalışmaya katılan 62 bireyin \%40.3'ü $(n=25)$ erkek, \%59.7'si $(\mathrm{n}=37)$ kadındır. Katılımcıların yaşı 21.9 \pm 1.1 yll, boyu $170 \pm 8.9 \mathrm{~cm}$, vücut ağırlığ $64.3 \pm 11.2 \mathrm{~kg}$ ve vücut kütle indeksi $22.1 \pm 2.5 \mathrm{~kg} / \mathrm{m}^{2}$ olarak hesaplanmıştır.

Birinci değerlendirici, ilk değerlendirmesinde "Sıçramadan Sonra Yere İnişte Hata Puanlama Sistemi-Gerçek Zamanlı" hata puanı olarak $6.84 \pm 1.85$ puan, ikinci değerlendirmesinde 6.94 \pm 1.93 puan vermiştir. İkinci değerlendirici, ilk değerlendirmesinde "Siçramadan Sonra Yere İnişte Hata Puanlama Sistemi-Gerçek Zamanlı" hata puanı olarak 6.37 \pm 1.46 
puan, ikinci değerlendirmesinde ise $6.37 \pm 1.72$ puan vermiştir (Tablo 1, Şekil 1). Değerlendirici içi ve değerlendiriciler arası güvenirliğinin iyi düzeyde olduğu saptanmıştır (Tablo 2).

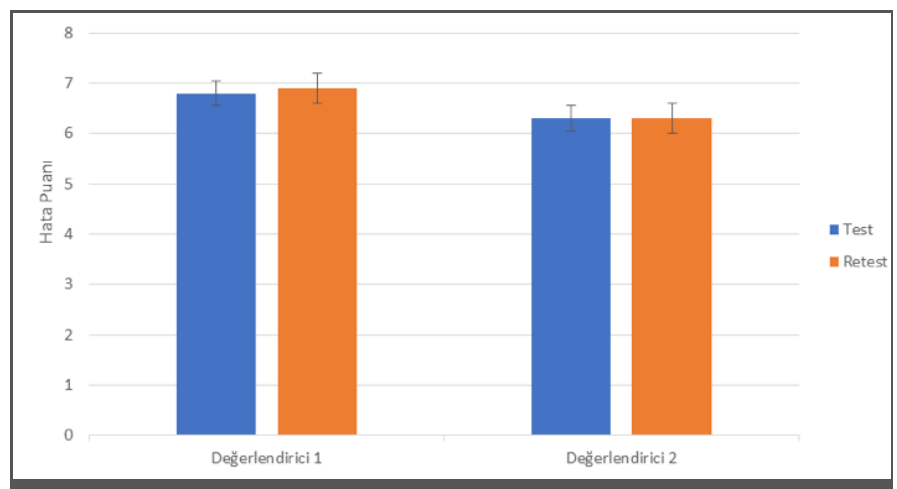

Şekil 1. Değerlendiricilerin belirlediği hata puanlarında zamansal tutarlık

Tablo 1. "Sıçramadan Sonra Yere İnişte Hata Puanlama Sistemi-Gerçek Zamanlı" hata puanları

$\begin{array}{cccc} & \begin{array}{c}\text { Test } \\ \text { (Ortalama } \pm \text { SS) }\end{array} & \begin{array}{c}\text { Re-test } \\ \text { (Ortalama } \pm \text { SS) }\end{array} & \text { p değeri }^{\text {a }} \\ \text { Değerlendirici }_{\mathbf{1}} & 6.84 \pm 1.85 & 6.94 \pm 1.93 & 0.59 \\ \text { Değerlendirici }_{\mathbf{2}} & 6.37 \pm 1.46 & 6.37 \pm 1.72 & 0.99 \\ \text { p değeri }^{\mathbf{b}} & 0.12 & 0.09 & \\ \text { a: bağımlı gruplarda t testi, b: bağımsız gruplarda t testi, SS: standart sapma }\end{array}$

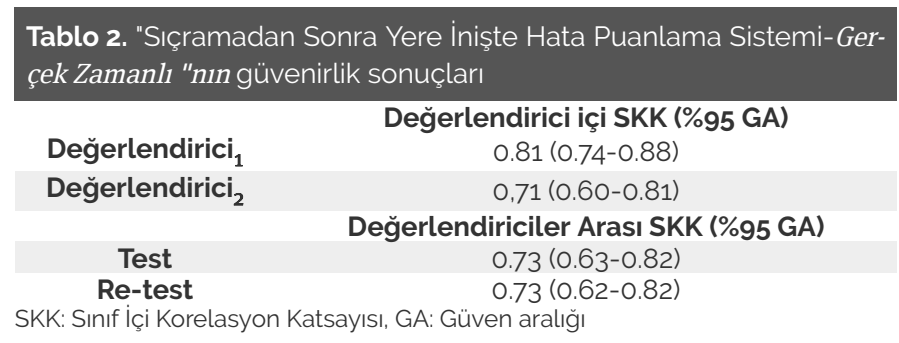

\section{TARTIŞMA}

Çalışmamızda "Sıçramadan Sonra Yere İnişte Hata Puanlama Sistemi-Gerçek Zamanlı"nın Türkçeye uyarlaması sağlanmıştır. Dilimize uyarlanan bu puanlama sisteminin, değerlendiriciler arasındaki güven düzeyinin iyi olduğu belirlenmiştir. Böylece alt ekstremite yaralanmaları riskini öngörebilecek Türkçe hata puanlama sistemi alan uzmanlar1nın kullanımına sunulmuş ve literatüre kazandırılmıştır.

Sportif hareketler sırasında hatalı hareket paternini objektif yöntemler ile belirlemek, yaralanmalardan korunmak için son derece önemlidir (1). Hareket analizi içeren klinik testler riski tarama ve tanımlama için kullanılabilmekte, aynı zamanda elde edilen test sonuçlarına göre koruyucu programlar da planlanarak sporcuların yaralanma riskleri azaltılabilmektedir (1). Bu amaçla kullanılabilen, geçerliğini ve güvenirliğini sağlamış testlerden biri olan "Sıçramadan Sonra Yere İnişte Hata Puanlama Sistemi", sporcuların sıçramadan sonra yere inişleri sırasındaki biyomekanik hata- larını belirlemeye yardımcı olmaktadır $(5,9)$. Bu sistem, özellikle temassız gelişen yaralanmaların riskini öngörebilmesi bakımından değerlidir $(4,9,10)$.

"Siçramadan Sonra Yere İnişte Hata Puanlama Sistemi"nin gerçek zamanlı kullanıma uygun halinin yakın zamanda literatüre kazandırılmış olması, literatürdeki çalışmalarda "Siçramadan Sonra Yere İnişte Hata Puanlama Sistemi-Gerçek Zamanlı"nın daha kısıtlı miktarda bulunmasına neden olmuştur (1). Ayrıca, literatür incelemesi sırasında belirleyebildiğimiz kadarıyla, "Sıçramadan Sonra Yere İnişte Hata Puanlama Sistemi-Gerçek Zamanlı"nın farklı dillere uyarlamasının henüz yapılmadığı belirlenmiştir. Dolayısıyla bu durum araştırmamıza, "Sıçramadan Sonra Yere İnişte Hata Puanlama Sistemi-Gerçek Zamanı"nın dil uyarlaması yapılan ilk çalışması olma özelliğini kazandırmıştır.

Diğer taraftan çalışmamızda elde edilen veriler, "Sıçramadan Sonra Yere İnişte Hata Puanlama Sistemi" kullanılarak yapılan araştırmalarla benzer bulunmuştur. Örneğin, Beese ve arkadaşları bireysel spor disiplinine katılan sağlıklı kadın adolesanlarda hata puanını $6.84 \pm 1.81$; takım sporu yapanlarda ise $6.07 \pm 1.93$ olarak belirlemiş, ancak gruplar arasında fark bulamamıştır (9). Yetişkinlerdeki çalışmaları inceleyen sistematik bir derlemede sunulan hata puanları da benzer şekilde bulunmuştur (11). Diğer bir çalışmada, yaş ortalaması 18.6 yıl olan fiziksel olarak aktif sağlıklı bireylerde tecrübeli değerlendirici tarafından verilen hata puanı $6.25 \pm 1.92$ iken tecrübesiz araştırıcı tarafından $3.79 \pm$ 2.12 puan verilmiştir ( $\left.\mathrm{p}^{<} \mathrm{0}, 001\right),(4)$. Bu açıdan, çalışmamızda sunulan hata puanı değerleri ve değerlendiricilerin sıçrama analizleri konusundaki tecrübe düzeyleri literatür ile uyumlu bulunmuştur.

"Siçramadan Sonra Yere İnişte Hata Puanlama Sistemi"nin geliştiricileri tarafından orijinal "Sıçramadan Sonra Yere İnişte Hata Puanlama Sistemi" kullanılarak yapılan araştırmada değerlendirici içi güvenirlik (Sınıf İçi Korelasyon Katsayısı 0.91) mükemmel, değerlendiriciler arası güvenirlik (Sınıf İçi Korelasyon Katsayısı o.84) ise iyi düzeyde uyum göstermektedir (12). "Siçramadan Sonra Yere İnişte Hata Puanlama Sistemi"nin 13 maddesi kullanılarak tecrübenin uyum düzeyine etkisinin değerlendirildiği bir başka çalışmada ise 5 yıllık "Sıçramadan Sonra Yere İnişte Hata Puanlama Sistemi" puanlama tecrübesi olan araştırıcı ile hiç tecrübesi olmayan araştırıcı arasında orta-mükemmel düzeyde (kappa korelasyon katsayısı=0.459-0.875) uyum belirlenmiştir (13). Öte yandan "Sıçramadan Sonra Yere İnişte Hata Puanlama Sistemi-Gerçek Zamanlı"daki uyum düzeylerinin o.72-0.81 ile orijinal "Siçramadan Sonra Yere İnişte Hata Puanlama Sistemi"ne göre daha düşük olduğu puanlama sisteminin geliştiricileri tarafından bildirilmektedir (5). Bu bilgiler ışığında, çalışmamızda elde edilen veriler literatür ile 
benzer uyum düzeyinde bulunmuştur. Böylece "Sıçramadan Sonra Yere İnişte Hata Puanlama Sistemi-Gerçek Zamanlı"nın Türkçeye uyarlandığı belirlenmiştir.

Çalışmamızda test-retest yönteminin kullanılabilmesi için video kayıt sistemlerinden yararlanılmış olması araştırmanın kısıtlılığını oluşturmuştur. Ancak hem test hem de retest değerlendiriciler arası sınıf içi korelasyon katsayısı değerinin 0.73 olması farklı zamanlardaki puanlama sonuçlarının benzer güvenirliğe sahip olduğu sonucuna ulaşmamızı sağlamıştır. Diğer taraftan "Sıçramadan Sonra Yere İnişte Hata Puanlama Sistemi-Gerçek Zamanlı"nın kullanımı sırasında "Bir ayak diğer ayaktan önce yerle temas ederse ya da bir ayağın teması topuktan ayak uçuna doğru ilerlerken diğeri ayak uçundan topuğa doğru ilerlerse" maddesinde (Ek 1) olduğu gibi gözün görme hızının sınırlarını aşan hızlı hareketlerin ayırt edilebilmesi konusunda zorlukların yaşanabilmesi bu sistemin dezavantajını oluşturmaktadır.

Sonuç olarak "Sıçramadan Sonra Yere İnişte Hata Puanlama Sistemi-Gerçek Zamanlı"nın Türkçeye uyarlaması sağlanmıştır. Böylece, sıçramadan sonra yere inişteki hataların saptanmasını kolaylaştıran pratik bir sistem, Türk araştırmacıların ve sporcu sağlığı ile ilgilenen sağlık profesyonellerinin kullanımına sunulmuştur.

\section{Acknowledgments / Teşekkür}

Sıçrama testlerinin uygulanması sırasındaki yardımları için Arş. Gör. Dr. Ayhan Canbulut'a, Uzm. Fzt. Mesut Ergan'a ve çalışmamıza katılan tüm gönüllülere teşekkür ederiz.

\section{Conflict of Interest / Çıkar Çatışması}

The authors declared no conflicts of interest with respect to authorship and/or publication of the article.

\section{Financial Disclosure / Finansal Destek}

The authors received no financial support for the research and/or publication of this article.

\section{KAYNAKLAR}

1. Schwartz O, Talmy T, Olsen CH, Dudkiewicz I. The Landing Error Scoring System Real-Time test as a predictive tool for knee injuries: A historical cohort study. Clin Biomech. 2020;73:11521.

2. Hébert-Losier K, Hanzlíková I, Zheng C, Streeter L, Mayo M. The "DEEP" landing error scoring system. Appl Sci.2020;10(3):1-13.

3. Everard E, Lyons M, Harrison AJ. Examining the Reliability of the Landing Error Scoring System With Raters Using the Standardized Instructions and Scoring Sheet. J Sport Rehabil. 2019;29(4):519-25.

4. Mauntel TC, Padua DA, Stanley LE, Frank BS, DiStefano LJ, Peck KY, et al. Automated quantification of the landing error scoring system with a markerless motion-Capture system. J Athl Train. 2017;52(11):1002-9.

5. Padua DA, Boling MC, DiStefano L, Onate JA, Beutler Al, Marshall SW. Reliability of the Landing Error Scoring System- Real Time, a Clinical Assessment Tool of Jump- Landing Biomechanics. J Sport Rehabil. 2011;20:145-56.

6. Sousa VD, Rojjanasrirat W. Translation, adaptation and validation of instruments or scales for use in cross-cultural health care research: A clear and user-friendly guideline. J Eval Clin Pract. 2011;17(2):268-74.

7. Lynn MR. Determination and quantification of content validity. Nurs Res. 1986;35:382-5.

8. David L. Instrument review: Getting the most from your panel of experts. Appl Nurs Res. 1992:5:194-7.

9. Beese ME, Joy E, Switzler CL, Hicks-Little CA. Landing error scoring system differences between single-sport and multi-sport female high school-aged athletes. $J$ Athl Train. 2015;50(8):806-11

10. Pointer CE, Reems TD, Hartley EM, Hoch JM. The ability of the landing error scoring system to detect changes in landing mechanics: A critically appraised topic. Int J Athl Ther Train. 2017;22(5):12-20

11. Hanzlíková I, Hébert-Losier K. Is the Landing Error Scoring System Reliable and Valid? A Systematic Review. Sports Health. 2020;12(2):181-8.

12. Padua DA, Marshall SW, Boling MC, Thigpen CA, Garrett WE, Beutler Al. The Landing Error Scoring System (LESS) is a valid and reliable clinical assessment tool of jump-landing biomechanics: The jump-ACL Study. Am J Sports Med. 2009:37(10):1996-2002.

13. Onate J, Cortes N, Welch C, Van Lunen B. Expert versus novice interrater reliability and criterion validity of the landing error scoring system. J Sport Rehabil. 2010;19(1):41-56. 
EK 1.

Sıçramadan Sonra Yere İnişte Hata Puanlama Sistemi-Gerçek Zamanlı

Açıklama: Bu ölçekte, maddelerin değerlendirileceği görüş açısı tablo içerisinde belirtilmektedir. Katılımcıya dört sıçrama yaptırılması ve dört sıçramanın her birinin ilgili maddelerde değerlendirilmesi gerekmektedir. Değerlendirme sonucunda; hata durumu tespit edildiğinde bazı durumlarda "1 puan (+1)", bazı durumlarda "2 puan (+2)" hata puanı verilmektedir. Katılımcı; toplamda en az o puan, en fazla 15 puan alabilir.

\section{Sıçramadan Sonra \\ Yere İnişte Hata \\ Puanlama Sistemi- \\ Gerçek Zamanli"nın maddeleri}

Duruș genișliği (iki ayak arası mesafe)

Maksimum ayak rotasyon pozisyonu

ilk temasta ayakların simetrisi

Maksimum diz valgus açısı Katı (+2).

\section{Maddenin açıklamas}

Değerlendirme frontal düzlemde yapılırken; katıımcı, (omuz genişliğine kıyasla) geniş veya dar duruş genişliği ile yere iniş yaparsa hata yapmış kabul edilir. Hata, duruş genișliği çok geniş veya çok dar ise puanlanır (+1).

Katılımcının ayakları, sıçramadan sonra yere inişin herhangi bir anında (temastan itibaren) orta düzeyde dış rotasyon veya hafifçe iç rotasyon yaparsa katılımcı hata yapmış kabul edilir (+1)

Bir ayak diğer ayaktan önce yerle temas ederse ya da bir ayağın teması topuktan ayak uçuna doğru ilerlerken diğeri ayak uçundan topuğa doğru ilerlerse katıımcı hata yapmış kabul edilir (+1).

Katılımcının dizinde, çok az miktarda valgus hareket oluşursa hata yapmış kabul edilir (+1).

tılımcının dizinde, fazla miktarda valgus hareket oluşursa hata yapmış kabul edilir

\section{Değerlendiricinin Maddenin görüș açısı değerlendirileceği sıçrama sırası}

$\begin{array}{ll}\text { Ön } & 1 \\ \text { Ön } & 1 \\ \text { Ön } & 1\end{array}$

Ön 2
Lateral gövde fleksiyonundaki değişimin miktarı

ilk temasta ayakların yere inişi

Diz fleksiyonundaki değişimin miktarı Gövde

fleksiyonundaki değişimin miktarı

Sagittal düzlemde (gövdedeki ve

dizdeki) tüm eklem hareketlerinin değişimi

Genel izlenim

Katılımcı, sağ veya sol tarafına doğru eğiliyorsa; yani gövde, frontal düzlemde dik pozisyonda değilse, hata yapmış kabul edilir (+1)

Katıımcı, yerle ilk temasını topuktan başlatıp ayak uçunda tamamlıyorsa ya da ayak tabanıyla yapıyorsa hata yapmış kabul edilir $(+1)$.

Katılımcı, diz fleksiyonunda çok az miktarda (+2) ya da bir miktar (+1) değişim yaparsa hata yapmış kabul edilir.

Katılımcı, gövde fleksiyonunda çok az miktarda (+2) ya da bir miktar (+1) değişim yaparsa hata yapmış kabul edilir.
Ön

Yan

Yan

Yan

Yan

Tümü

2

3

4
Katıımcı, gövde ve diz ekleminde fazla miktarda hareket yaparsa eklem hareketi

değişimi yumuşaktır (o). Katılımcı, gövde ve diz ekleminde bir miktar hareket

yaparsa eklem hareketi değişimiortadır (+1). Katılımcı, çok az miktarda gövde ve diz eklem hareketi yaparsa (veya hiç hareket yapmazsa) eklem hareketi değişimi serttir (+2).

Katılımcı, yumuşak bir iniş gerçekleştirir ve frontal düzlemde diz hareketi gözlenmezse iniş mükemmeldir (o). Katılımcı, sert bir iniş gerçekleştirir ve frontal düzlemde fazla miktarda diz hareketi gözlenirse ya da (sert bir iniș gerçekleştirmese bile) sadece frontal düzlemde fazla miktarda diz hareketi olursa iniş kötüdür (+2). Diğer tüm inişler için iniş ortadır (+1) 
EK 2.

Sıçramadan Sonra Yere İnişte Hata Puanlama Sistemi-Gerçek Zamanlı Puanlama Tablosu

Frontal düzlem hareketleri

1. Duruş genişliği (iki ayak arası mesafe)

$\underline{\text { Sagittal düzlem hareketleri }}$

$\square$ Normal (o)
$\square$ Geniş (1)
$\square$ Dar (1)

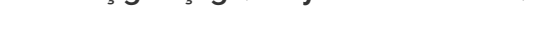

3. ilk temasta ayakların simetrisi

$\square$ Simetrik (o)

$\square$ Simetrik değil (1)

6. ilk temasta ayakların yere inişi

- Ayak uçundan başlayıp topuğa (o)

- Topuktan başlayıp ayak uçuna (1)

$\square$ Ayak tabanıla (1)

$\square$ Fazla (o)
$\square$ Bir miktar (1)
$\square$ Çok az (2)

7. Diz fleksiyonundaki değişimin miktarı

$\square$ Fazla (o)

口 Bir miktar (1)

$\square$ Çok az (2)

4. Maksimum diz valgus açısı

8. Gövde fleksiyonundaki değişimin miktarı

4. Maksimum diz valgus açısı
$\square$ Yok (o)
$\square$ Çok az (1)
$\square$ Fazla (2)
$\quad$ 5. Lateral gövde fleksiyonundaki değişimin miktarı
$\square$ Yok (o)
$\square$ Çok azdan bir miktara (1)
9. Sagittal düzlemde (gövdedeki ve dizdeki) tüm eklem
hareketlerinin değişimi

$\square$ Yumuşak (o)

$\square$ Orta (1)

$\square$ Sert (2)

$\square$ Mükemmel (o)

$\square$ Orta (1)

$\square$ Kötü (2) 